\title{
Acquired Hypothyroidism
}

National Cancer Institute

\section{Source}

National Cancer Institute. Acquired Hypothyroidism. NCI Thesaurus. Code C129644.

Hypothyroidism, the cause of which is not present at birth. 